\title{
Why the Greenwich meridian moved
}

\author{
Stephen Malys ${ }^{1}$ - John H. Seago ${ }^{2}$ - Nikolaos K. Pavlis ${ }^{1}$ - P. Kenneth Seidelmann ${ }^{3}$. \\ George H. Kaplan ${ }^{4}$
}

Received: 30 March 2015 / Accepted: 21 July 2015 / Published online: 1 August 2015

(C) The Author(s) 2015. This article is published with open access at Springerlink.com

\begin{abstract}
In 1884, the International Meridian Conference recommended that the prime meridian "to be employed as a common zero of longitude and standard of time-reckoning throughout the globe" pass through the "centre of the transit instrument at the Observatory of Greenwich". Today, tourists visiting its meridian line must walk east approximately $102 \mathrm{~m}$ before their satellite-navigation receivers indicate zero longitude. This offset can be accounted for by the difference between astronomical and geodetic coordinates-deflection of the vertical-in the east-west direction at Greenwich, and the imposed condition of continuity in astronomical time. The coordinates of satellite-navigation receivers are provided in reference frames that are related to the geocentric reference frame introduced by the Bureau International de l'Heure (BIH) in 1984. This BIH Terrestrial System provided the basis for orientation of subsequent geocentric reference frames, including all realizations of the World Geodetic System 1984 and the International Terrestrial Reference Frame. Despite the lateral offset of the original and current zerolongitude lines at Greenwich, the orientation of the meridian plane used to measure Universal Time has remained essentially unchanged.
\end{abstract}

Stephen Malys

stephen.malys@nga.mil

1 National Geospatial-Intelligence Agency, 7500 GEOINT Dr., Springfield, VA 22150, USA

2 Analytical Graphics, Inc., 220 Valley Creek Blvd, Exton, PA 19341-2380, USA

3 Astronomy Department, University of Virginia, P.O. Box 400325, Charlottesville, VA 22904, USA

4 United States Naval Observatory, 3450 Massachusetts Avenue, N.W., Washington, DC 20392, USA
Keywords Greenwich meridian - Deflection of the vertical · Prime meridian - ITRF zero meridian · IERS Reference Meridian - International Reference Meridian . International Terrestrial Reference Frame · Greenwich Mean Time

\section{The situation at Greenwich}

The Airy Transit Circle is a nineteenth-century telescopic instrument at the Royal Observatory, Greenwich, famous as the origin for global longitude. Recognized as a place of world heritage by UNESCO, the observatory is now a museum with a line in the pavement running north to south, and with signage marking it as the "Prime Meridian of the World". Today, its longitude is $00^{\circ} 00^{\prime} 05.3^{\prime \prime} \mathrm{W}$ (Howse 1997) in the International Terrestrial Reference Frame (ITRF), and in the World Geodetic System (WGS 84) used by the U.S. Global Positioning System (GPS). The observatory's nonzero longitude is widely noticed by tourists with satellitenavigation receivers, and by people using software to display geo-referenced imagery or maps of the Earth. The ground trace of the WGS 84 and the ITRF zero-longitude meridian plane is located approximately $102 \mathrm{~m}$ east of the telescope (Fig. 1). The apparent discrepancy raises questions of how and when it arose, and whether a worldwide system of longitude has been systematically shifted by this same amount.

In Sects. 2 and 3, the authors show that the deflection of the vertical (DoV) can account for the entire longitude shift at Greenwich. In Sect. 4, the authors also compare astrogeodetic and gravimetric DoVs and their uncertainties, using a recent global gravitational model, for a number of astronomical observatories that contributed to past determinations of UT1. This provides information about the overall orientation between the former (astronomical) and modern (geodetic) 


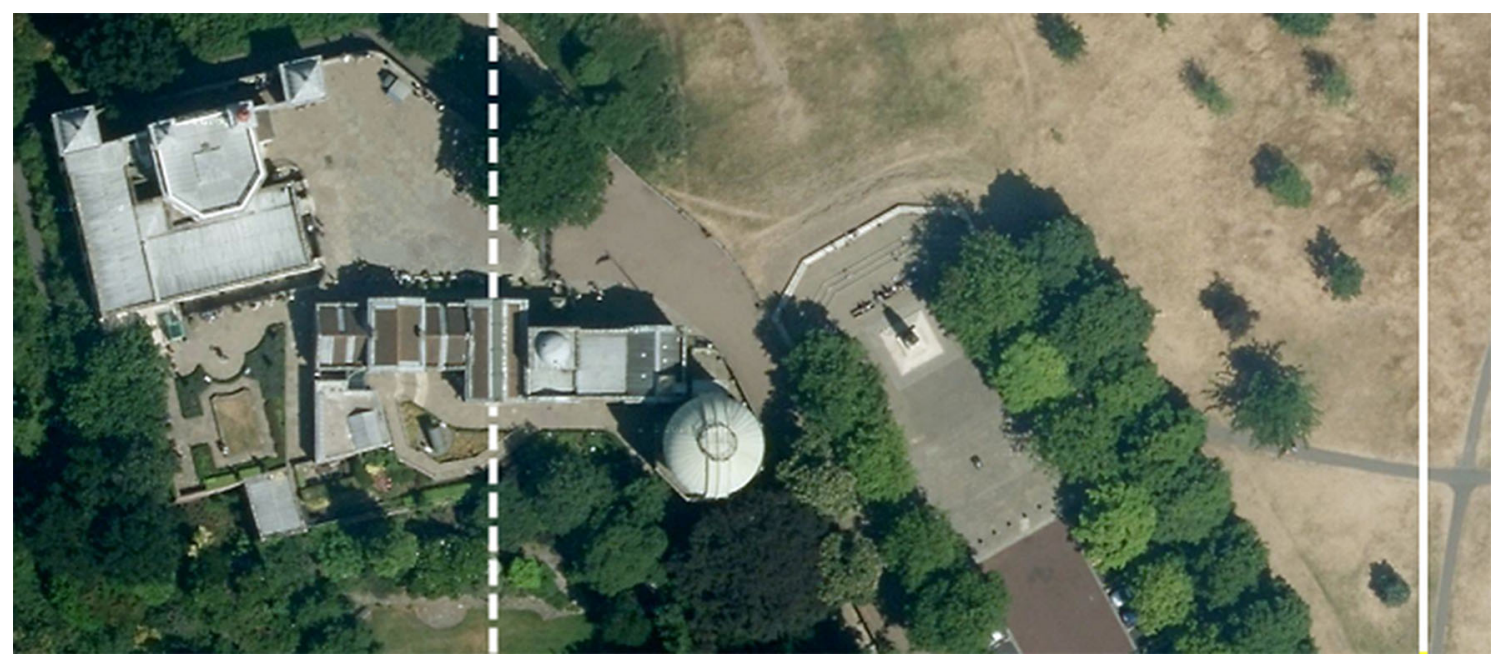

Fig. 1 The Airy meridian (dotted line) and the ITRF zero meridian (solid line). Imagery@ 2014 Google Maps, Infoterra Ltd \& Bluesky

longitude systems. Because books for the general public (e.g., Malin and Stott 1989; Howse 1997; Jennings 1999; Dolan 2003; Murdin 2009), as well as the web sites of the UK's National Maritime Museum (Sinclair 1997) and Wikipedia (IERS Reference Meridian 2014), either ignore the longitude offset at Greenwich, acknowledge it but do not assign a cause, or provide incorrect accounts, the authors also consider some of the conjectured explanations in Sect. 5.

\section{Methods of determining longitude and Earth rotation}

Traditional optical instruments for measuring Earth rotation included visual and photographic zenith tubes, circumzenithals, Danjon astrolabes, and transit telescopes, such as the Airy Transit Circle. These instruments measured local sidereal time by the passage of specially designated "clock stars" across a plane of reference established in part by the local direction of gravity. These measurements were realized with respect to the local vertical using a basin of mercury, and the astronomical latitudes and longitudes of the observatories were thus affected by local gravity, because their coordinates were determined from the same observations.

The sidereal time observed from these instruments was converted to mean solar time according to a conventional relationship, and time signals were adjusted to match the astronomical observations. The difference between astronomically determined local mean times $t$ (in hours) is proportional to the difference in local longitudes $\Lambda$ (in degrees):

$t-t_{0}=\left(\Lambda-\Lambda_{0}\right) / 15$

where $\Lambda_{0}$ and $t_{0}$ refer to the astronomical longitude and time of the reference, or "prime", meridian. The 1884 Interna- tional Meridian Conference recommended that the prime meridian, $\Lambda_{0}=0$, pass through the Airy Transit Circle at Greenwich (Explanatory Supplement 1961), establishing the mean solar time determined at the Airy Transit Circle-Greenwich Mean Time (GMT)_as an internationally recognized basis for global timekeeping and navigation. Any astronomical time service could thereby convert its own determination of local mean time to GMT by removing its longitude difference from Greenwich.

Because of significant discrepancies between the earliest radio time-signal broadcasts, the Bureau International de l'Heure (BIH) was established at the Paris Observatory in 1912 to help coordinate the national time bureaus and improve longitudes globally (Guinot 2000). For purposes of global timekeeping by the $\mathrm{BIH}$, the Greenwich Observatory was superseded in 1929 by a statistical construct known as the "mean observatory", of which Greenwich became one of many contributors. The formation of GMT, now called Universal Time, from this "mean observatory" involved adopted corrections to the contributed data and weights that could change annually (Feissel 1980). To maintain a continuous and consistent series of Universal Time, the BIH also assumed the responsibility for establishing and refining the terrestrial reference systems used for the analyses (Guinot 2000). The early BIH terrestrial reference frames were entirely based on astronomical coordinates (Mueller 1969).

Delays in the analysis of polar motion from the International Latitude Service (ILS) made it impractical for the $\mathrm{BIH}$ to correct Universal Time for the motion of the rotational pole until the middle of the twentieth century (Guinot 2000). Universal Time observed from a given observatory was designated UT0, whereas the distributed astronomical time scale corrected for polar motion became known as UT1. After the BIH adopted various reference poles of different epochs during the 1950s and 1960s (Robbins 1967), the BIH 
standardized on the average ILS pole from 1900-1905known as the Conventional International Origin-as part of an update to celestial and terrestrial reference systems. To preserve the continuity of UT1-UT0 for contributing stations within this new "1968 BIH System", the adopted longitudes of observatories were systematically adjusted for the change of pole. Although the Airy Transit Circle was no longer operational as a BIH station, its astronomical longitude would have changed from zero to $0.2927^{\prime \prime} \mathrm{W}$ (about $6 \mathrm{~m}$ ) within this new system (MacDonald 1985; Schmid 1974).

Beginning in 1973, the BIH began incorporating estimates of polar motion from the U.S. Navy TRANSIT (satellite Doppler) navigation system into its own processes (Guinot 1979). Other experimental techniques, such as Very Long Baseline Interferometry (VLBI), connected-element radio interferometry, and lunar laser ranging (LLR) were gradually introduced along with the traditional optical measurements to estimate UT1. By 1984, the BIH discounted optical astrometry completely, and established a new terrestrial coordinate system designated as the "BIH Terrestrial System", or BTS 84 (BIH 1985). This system was based on weighted solutions of Earth-orientation parameters from analysis centers and networks of VLBI, SLR and LLR geodetic stations that were independent of the former network of optical systems (Boucher and Altamimi 1985, 1986). In constructing BTS 84, the solution of network orientation (and thus its corresponding meridian of zero longitude) was constrained to match the ensemble of Earth-orientation measurements made from 1980 through 1983 relative to atomic timekeeping. Thus, the series of UT1 determinations based on non-traditional techniques maintained continuity with the former series dominated by optical astrometry (within the uncertainty of the optical measurements).

By 1988, the BIH and the International Polar Motion Service (successor to the ILS) were both replaced by the International Earth Rotation Service (IERS) (Wilkins 2000), which assumed responsibility for maintaining the terrestrial and celestial reference frames consistent with the Earthorientation parameters it published routinely. The subsequent terrestrial reference frames of the IERS-in particular, the various realizations of the International Terrestrial Reference Frame (ITRF) - preserve the orientations relative to the reference meridian of the BTS (see Jekeli 2006, pp. 3-14). Modern geodetic reference frames, such as the ITRF, are defined by the Cartesian position and velocity coordinates of an ensemble of stations in three dimensions. Within this context, the corresponding reference (zero) meridian is the Earth-fixed $X-Z$ plane, where longitude is measured around the $Z$-axis eastward from that plane. The IERS Conventions (IERS 2010) recommend the term 'ITRF zero meridian' for this plane, although the terms 'IERS Reference Meridian' and 'International Reference Meridian' (IRM) are also in use.

\section{Astrogeodetic and gravimetric DoV determination}

Natural coordinates $[\Phi, \Lambda, H]$ are related to geodetic latitude, $\varphi$, longitude, $\lambda$, and ellipsoidal height $h$, by (Heiskanen and Moritz 1967):

$$
\left.\begin{array}{lr}
\xi=\Phi-\varphi & (a) \\
\eta=(\Lambda-\lambda) \cos \varphi & (b) \\
N=h-H & (c)
\end{array}\right\},
$$

where, $\xi$ is the meridional component of the $\mathrm{DoV}, \eta$ the prime vertical component of the DoV and $N$ is the geoid undulation. These equations relate the geodetic quantities $[\varphi, \lambda, h]$ to the physical quantities $[\Phi, \Lambda, H]$ associated with the gravity field. If the geodetic coordinates $[\varphi, \lambda, h]$ of a point have been determined with respect to a given datum, and if the natural coordinates $[\Phi, \Lambda, H]$ have been determined also (e.g., from astronomical observations and from spirit leveling), then one can obtain the deflection components $\left(\xi_{\text {astro }}\right.$, $\left.\eta_{\text {astro }}\right)$ and the geoid undulation $(N)$ at that point from Eq. (2). Today, such a geometric determination can be realized by making astronomical observations of $\Phi$ and $\Lambda$ at a point whose geodetic coordinates $[\varphi, \lambda, h]$ have been determined from GNSS positioning, and whose orthometric height, $H$, has been determined from spirit leveling. Such a geometric determination yields astrogeodetic DoV components that are specific to the particular datum to which the geodetic coordinates, $\varphi$ and $\lambda$, refer.

The DoV components $(\xi, \eta)$ also represent the slopes of the geoid surface with respect to the surface of an equipotential reference ellipsoid along the meridian and the prime vertical, respectively, (Heiskanen and Moritz 1967, section 2-22):

$$
\left.\begin{array}{ll}
\xi_{\text {grav }}=-\frac{\partial N}{R \partial \varphi} & (a) \\
\eta_{\text {grav }}=-\frac{\partial N}{R \cos \varphi \partial \lambda} & (b)
\end{array}\right\},
$$

where $R$ is a mean Earth radius. The sign convention in Eqs. (2) and (3) is such that $\xi$ is positive when the astronomical zenith, $Z_{\mathrm{a}}$, is north of the geodetic zenith, $Z_{\mathrm{g}}$; and $\eta$ is positive when $Z_{\mathrm{a}}$ is east of $Z_{\mathrm{g}}$ (Torge 2001, p. 219). These slopes can be determined gravimetrically, either using the integral formulas of Vening Meinesz, or using a spherical harmonic representation of the Earth's gravitational potential. The gravimetric determination of DoV requires dense measurements of gravity and detailed mapping of the topography near the computation point for the effective use of the integral formulas, or, equivalently, a very high degree and 


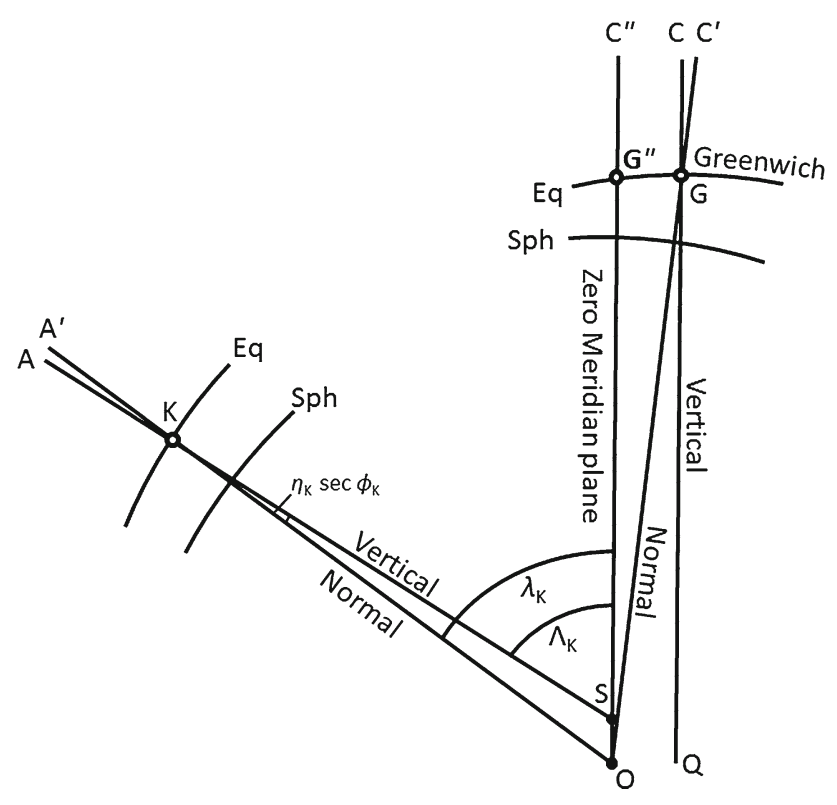

Fig. 2 The reference ellipsoid from a point on its minor axis above the north pole. $O=$ spheroid axis passing through the geocenter, Eq $=$ ground level equipotential surface, $\mathrm{Sph}=$ spheroidal parallels, $O A^{\prime}=$ geodetic meridian plane at $K, S A=$ astronomical meridian plane at $\mathrm{K}$ (Bomford 1980)

order gravitational field model. EGM2008 is a gravitational model that is complete to spherical harmonic degree 2190 and order 2159 (Pavlis et al. 2012) and carries enough resolving power to support the determination of gravimetric deflections with adequate accuracy, to estimate the astronomical coordinates for the Airy Transit Circle by:

$$
\left.\begin{array}{lr}
\Phi_{\text {grav }}=\varphi+\xi_{\text {grav }} & (a) \\
\Lambda_{\text {grav }} & =\lambda+\eta_{\text {grav }} \cdot \sec \varphi(b)
\end{array}\right\}
$$

These "synthetic" astronomical coordinates can then be compared to independent astronomical observations. If the orientation of the zero meridian plane is the same for both astronomical and geodetic longitudes, Eqs. (2b) and ( $3 b$ ) will yield consistent values for $\eta$ (Bomford 1980, p. 100).

The authors used the EGM2008 spherical harmonic coefficients to degree 2190, and calculated the deflections at Greenwich via harmonic synthesis, to obtain $\xi_{\text {grav }}=2.156^{\prime \prime}$ and $\eta_{\text {grav }} \cdot \sec \varphi=5.502^{\prime \prime}$ assuming zero elevation, a result which agrees with the estimates of $2.15^{\prime \prime}$ and $5.51^{\prime \prime}$ made by Ekman and Agren (2010) via numerical differentiation of the gridded version of the EGM2008 geoid. The results predict an astronomical longitude of $\Lambda_{\text {grav }}=00^{\circ} 00^{\prime} 00.19^{\prime \prime} \mathrm{E}$ for the Airy Transit Circle. Within the estimated EGM2008 commission error in $\eta_{\text {grav }} \sec \varphi, \pm 0.47^{\prime \prime} 1 \sigma$ (see also Pavlis et al. 2012, section 5), the predicted astronomical longitude is in good agreement with its originally adopted value of zero.

Figure 2 illustrates the reference ellipsoid as seen from a vantage point along its minor axis above the north pole (point $O$ ). The line-segment $\mathrm{QC}$ identifies the plane of the astronomical reference meridian of Greenwich, $\Lambda=0$. It is parallel to $O C^{\prime \prime}$, the plane of the geodetic reference meridian of $G^{\prime \prime}, \lambda=0$. The angle $C^{\prime} O C^{\prime \prime}$ is exactly $\eta \cdot \sec \varphi$, the eastwest component of the DoV at Greenwich, projected onto the equator. As illustrated, the shift eastward at Greenwich represents only a lateral transfer of the trace of the geodetic longitude $\lambda=0$ meridian across the surface of the Earth. Thus, the geodetic prime meridian at Greenwich has the same orientation as a function of time as the astronomical meridian. In order for the plane of the geodetic prime meridian to pass through the geocenter, its trace on the ground in the vicinity of Greenwich must move to the east by about $102 \mathrm{~m}$, the sign and magnitude of which is correctly predicted by EGM2008.

\section{Astrogeodetic and gravimetric DoV comparisons}

The astrogeodetic deflection $\eta_{\text {astro }}$ from Eq. (2b) can be expected to agree with its corresponding gravimetric value $\eta_{\text {grav }}$ only if the astronomical and geodetic origins of longitude are parallel planes. This condition is not guaranteed in principle (see also Tscherning 1986), but it can be tested at surface points where gravimetric determinations of $\eta$ have been made, and where astronomical and geodetic longitudes $\Lambda$ and $\lambda$ are both determined. The difference $\Delta \eta=\eta_{\text {astro }}-$ $\eta_{\text {grav }}$ includes errors in the determination of the coordinates, as well as errors of commission and omission in the gravimetric deflection. For a meaningful test, these errors should be small relative to the magnitude of any supposed misalignment of the longitude origin.

A slightly different, but equivalent, approach follows from Ekman and Agren (2010), who "synthesized" astronomical coordinates per Eq. (4), and then compared values of $\Lambda_{\text {grav }}$ to the historical astronomical longitudes $(\Lambda)$. For fundamental observatories at Stockholm, København, and Greenwich, their results indicated differences between $\Lambda$ and $\Lambda_{\text {grav }}$ of $0.4^{\prime \prime}, 0.9^{\prime \prime}$, and $0.2^{\prime \prime}$, respectively. Here, the authors extended this approach by correcting the conventional BIH coordinates of astronomical stations before 1984 (1968 BIH System) for local deflection, and then comparing the corrected coordinates to their geodetic coordinates with respect to WGS 84 . If the origin for longitude was the same both before and after 1984 , then the longitude residual $\Lambda-\Lambda_{\text {grav }}$ for each BIH optical station should be small relative to the uncertainty of its estimated deflection, $\sigma_{\eta \cdot \sec \varphi}$.

Consideration was limited to optical stations that could be confidently identified, and also contributed to the BIH determination of UT1 prior to BTS 84 (Table 1). Where geodetic coordinates were unavailable, the authors resorted to satellite imagery available via virtual globe services (e.g., Google Earth $^{\mathrm{TM}}$, Bing ${ }^{\mathrm{TM}}$ Maps, etc.) to approximate the geodetic longitude of extant shelters or their ruins. For stations that were 


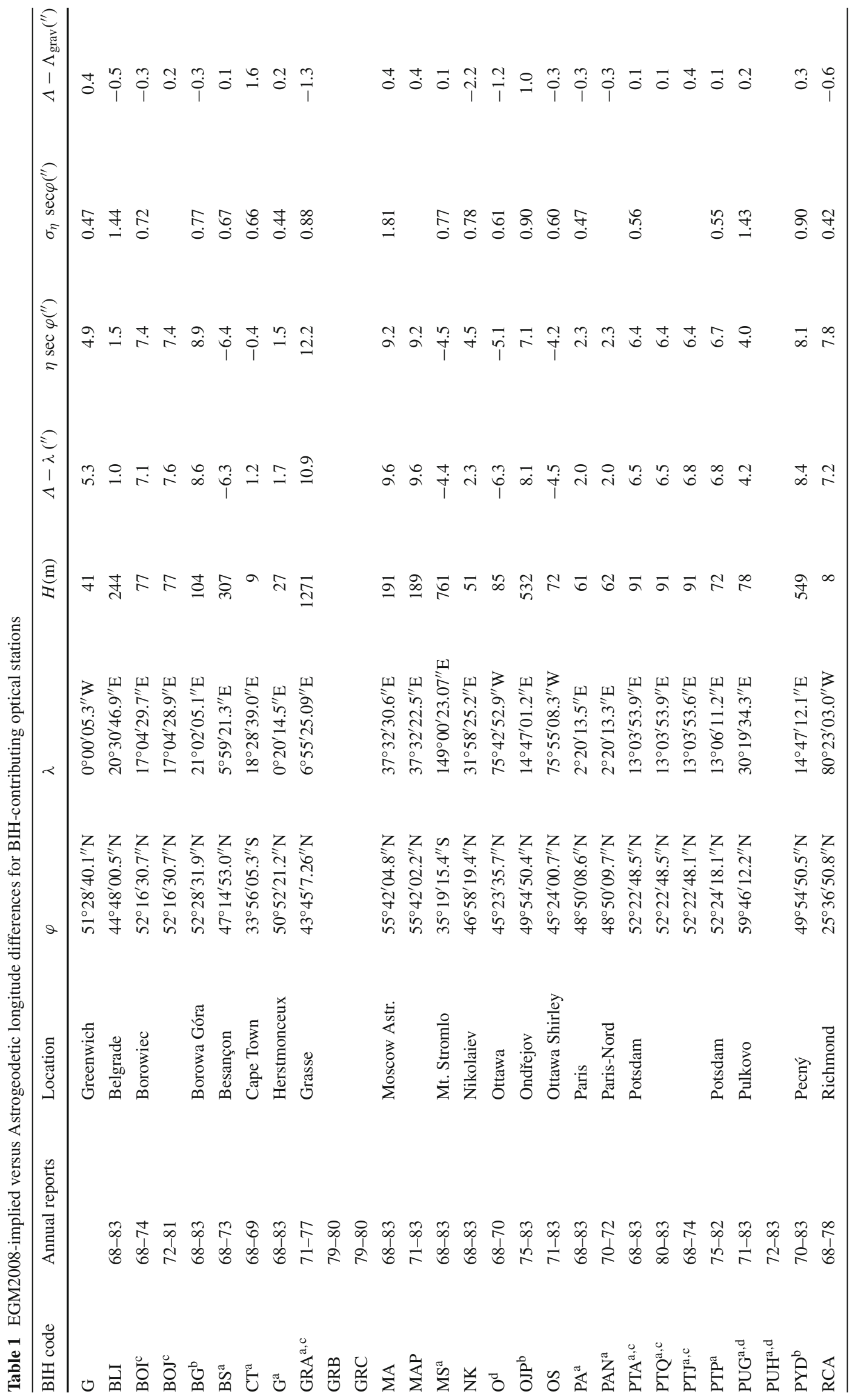




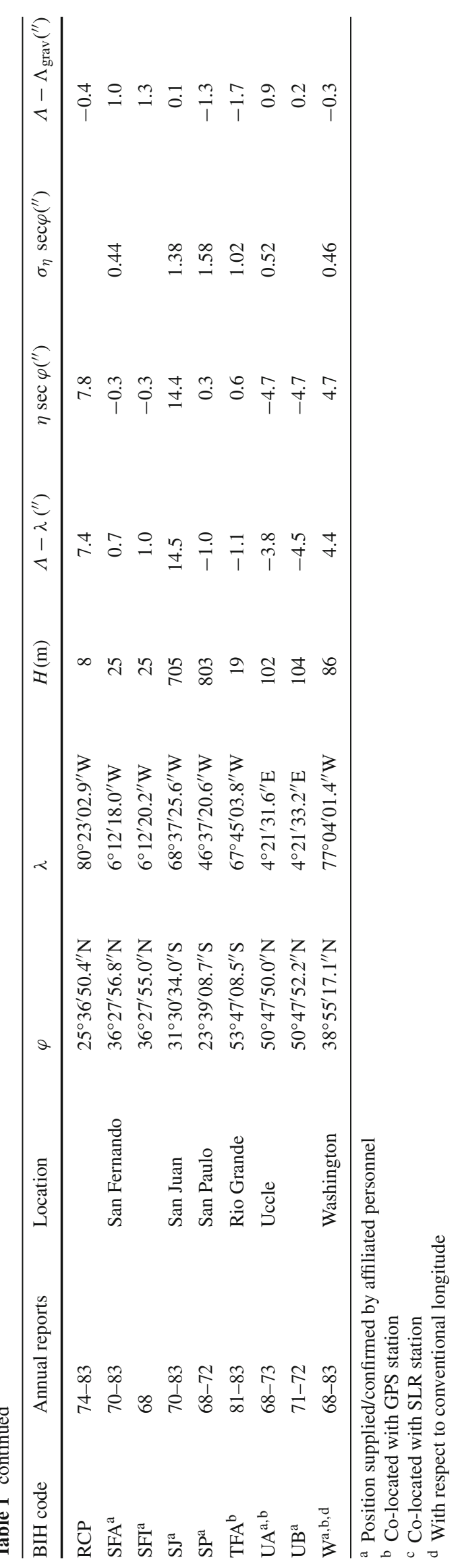


co-located with geodetic observatories, the precise ITRF coordinates of nearby GPS or SLR stations confirmed that geolocation errors of the virtual globes were at the level of a few meters, which is generally below the uncertainty in $\eta_{\text {grav }}$ for EGM2008. In most cases, affiliated personnel provided corroboration of extant structures, or geodetic coordinate estimates based on historic local surveys or GPS readings; this was the only means of positioning some long-demolished stations.

For the analysis, astronomical longitudes were adopted from BIH annual reports between 1968 and 1983, except that of Washington (W), which was adopted from Hughes et al. (1975). Small annual and semi-annual coordinate corrections estimated by BIH, which could have been due to a combination of systematic errors (errors in catalogued star positions, instrumentation, and/or adopted longitude), were ignored. The final computation of $\eta_{\text {grav }}$ used station elevations interpolated from the ERTM2160 data set ${ }^{1}$ (Hirt et al. 2014), and included the ERTM2160 component of $\eta$ to reduce the EGM2008 omission errors. However, neglecting the effect of elevation, and the effect of ERTM2160 on $\eta$, does not appreciably change the overall statistics, as only a few stations greatly exceed the average elevation of approximately $200 \mathrm{~m}$, or experience highly variable terrain.

For all BIH stations investigated, the longitude differences $\Lambda-\Lambda_{\text {grav }}$ were found to be within $\pm 3 \sigma$ of the EGM2008 commission error estimate (Table 1). The weighted average of $\Lambda-\Lambda_{\text {grav }}$ was statistically no different than zero $\left(0.06^{\prime \prime} \pm 0.14^{\prime \prime} 1 \sigma\right)$, the weights being the reciprocal values of the EGM2008-implied commission error variances of $\eta_{\text {grav }} \sec \varphi$. Both results support the current placement of zero longitude as being due to the local deflection of the vertical at Greenwich, with no change in orientation occurring at the time of changeover to the BTS 84 .

\section{Other conjectured explanations}

Since the 1960s, realizations of zero longitude from spacegeodetic reference systems have tended to be east of the Airy Transit Circle by an amount that is close to the vertical deflection at Greenwich (Fig. 3). This offset is mostly a consequence of artificial-satellite operations requiring the plane for the origin for UT1 to pass through the center of mass of the Earth. In 1969, Gebel and Matthews (1971) observed a longitude difference of 5.64" between the Airy Transit Circle and zero longitude of the TRANSIT navigation system; at the time, it was conjectured that DoV at Greenwich contributed to the offset. Relative to the BIH origin for UT1 (e.g., segment $O C^{\prime \prime}$ in Fig. 2), TRANSIT's zero longitude was further assumed to be "quite close, i.e., about 1 " apart, based on cer-

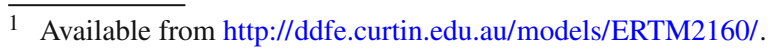

tain reasonable assumptions", although the details behind this assessment were not published. This proximity was simply fortuitous: the original longitude reference for TRANSIT's datum was implicitly defined by a regional NAD 27 survey of the TRANSIT antenna site (APLMND) at Applied Physics Laboratory (APL), in Laurel, Maryland, USA, where the longitude difference between NAD 27 and WGS 84 in the vicinity of the APL is about 1.2" (Fig. 3), as estimated by the authors. Later, Dillon et al. (1977) adjusted the TRANSIT station network to improve compatibility with WGS 72.

The authors have also identified one internet article (Mautz 2004) suggesting DoV as a probable source for the offset observed with GPS from Airy's meridian line. Nevertheless, the early research of Gebel and Matthews (1971) has fueled an increasingly popular opinion that APL's choice of longitude reference for TRANSIT promulgated a 6 " offset into subsequent global satellite datums, such as WGS 84 (IERS Reference Meridian 2014). In reality, the early geodetic reference frames of TRANSIT never influenced the longitudinal orientation of WGS 84; rather, WGS 84 was consistently oriented by the BIH directional origin for UT1 via BTS 84 , a global datum independent of TRANSIT (BIH 1985, p. B6, Table 3; Defense Mapping Agency 1987; Malys 1988). The latest realizations of WGS 84 are aligned with the ITRF established by the IERS (Wong et al. 2012; NGIA 2014), which also evolved from BTS 84 .

Another conjecture for the longitude offset is that significant errors crept into the BIH timekeeping process gradually during the twentieth century. When the Airy Transit Circle began to experience noticeable problems due to its age, the British Time Service transitioned its timekeeping program to other, smaller transits after July, 1927 (Gething 1954). The Airy Transit Circle was already out of regular timekeeping service when the BIH began using its "mean observatory" to determine UT, so the lack of direct contribution has been theorized to have allowed zero longitude to drift away from Airy's transit. However, the supplementary instruments at Greenwich were subject to the same vertical deflection, and continued to be assigned a conventional longitude of exactly zero by the BIH (BIH 1933, and subsequent), with their observations being adjusted for their longitude separation from Airy's instrument. When the Royal Greenwich Observatory (RGO) astronomical station was moved from Greenwich to Herstmonceux in 1957, its photographic zenith tube was assigned whatever conventional value of longitude gave the best continuity with the established time services. This would have eliminated the discontinuity normally expected with a change of instrument (Atkinson 1957). Although some of the processes used by the BIH were not transparent to users, any systematic shifts in the zero longitude were apparently limited to a few milliseconds in time at most (Mueller 1969; Guinot 2000). This level of reported 


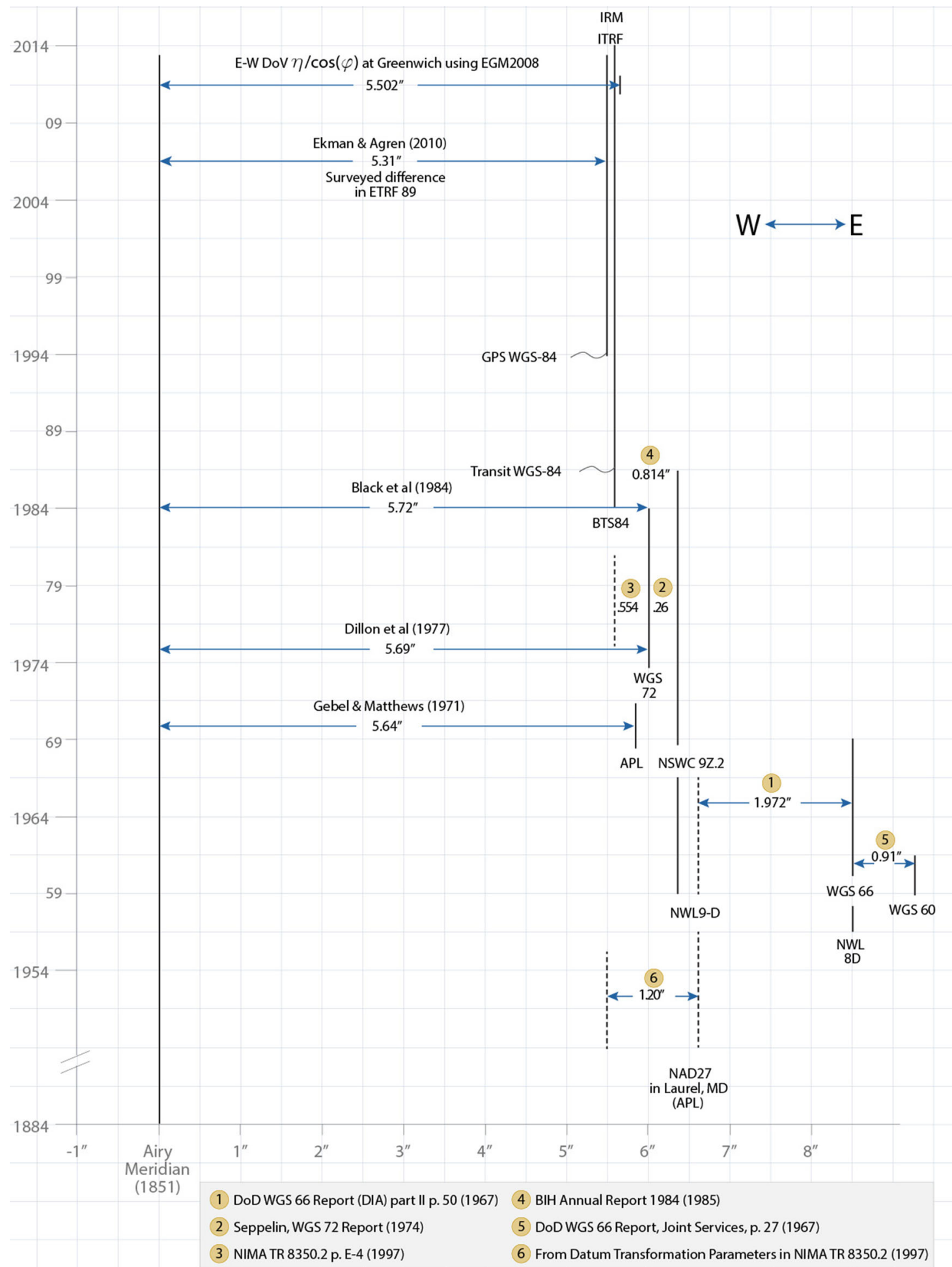

Fig. 3 Selected offsets among prime meridians from the "Space Age" and the Airy Transit Circle. The yellow circle provides a reference for each documented offset

accuracy is in contrast to the current $102 \mathrm{~m}$ offset, which would be more than $1 / 3 \mathrm{~s}$ in time.

Polar motion, which has been well measured since the late nineteenth century, cannot account for the shift of the prime meridian. The amplitude of the periodic part of polar motion is about 0.3 arc-second, and the drift of the mean rotational pole is currently about 0.5 arc-second/century toward the western hemisphere (IERS 2014). The effect of polar motion 
on the longitude at Greenwich is less than one arc-second. Crustal motion from plate tectonics is also much too small to explain the observed longitude difference. Britain and most of Europe are moving toward the northeast at about $3 \mathrm{~cm} / \mathrm{year}$ (a longitude change of 0.1 arc-second/century) with respect to the WGS 84 terrestrial coordinate frame (Altamimi et al. 2012). The accumulated effect relative to other monitoring stations amounts to only a few meters since its designation as prime meridian in 1884 .

Improvements in the fundamental celestial reference frame and in astronomical computations for positional astronomy were introduced in 1984 after 10 years of planning (Kaplan 1981 and references therein), but there is no evidence that these changes affected the geodetic longitude system now in use. These changes were generally of the order of one arc-second at the changeover date. Although small, the changes had the potential to affect UT1 determinations and, therefore, the longitude system of BTS 84 . However, the International Astronomical Union specified that there be no change in the value or rate of UT1 due to the new scheme (IAU 1977, 1980), so that the conventional expression for sidereal time in terms of UT1 was modified to provide continuity in the UT1 determinations (Aoki et al. 1982).

\section{Conclusion}

Zero longitude is the terrestrial origin for Universal Time (UT1), a realization of mean solar time at Greenwich used to define the rotation angle of the Earth in space. The 102-m offset between the Airy Transit Circle and zero longitude indicated by a GNSS receiver is attributable to the fact that continuity in the UT1 time series was maintained in the BIH reference frames, as geodetic longitudes replaced astronomical longitudes when space-geodetic methods were introduced. This continuity condition constrained the BTS 84, and consequentially, the ITRF zero meridian plane, to be practically parallel to the orientation of the astronomical prime meridian through Airy's instrument that is aligned to local gravity. Extended to infinity, these parallel meridian planes sweep past the same stars simultaneously, so that both planes indicate the same astronomical time (UT1). The difference between precise GNSS coordinates and astronomically determined coordinates everywhere remains a localized gravity effect due to the deflection of the vertical; thus, no systematic rotation of global longitudes occurred between the former astronomical system and the current geodetic system.

Because the value of the DoV at Greenwich and the continuity constraint on UT1 were the primary factors that influenced the current location of the ITRF zero meridian, the 1884 recommendation of a prime meridian based on the "Observatory in Greenwich" has been practically maintained to the present by passing the zero meridian plane through the center of mass of the Earth, rather than through the center of the Airy Transit Circle. Modern, high-resolution global gravitational models of the Earth confirm that the local slope of the geoid at Greenwich is of the proper sign and magnitude to support this interpretation, conclusive to within the accuracy of the deflection model $\left( \pm 0.5^{\prime \prime} 1 \sigma\right.$ in longitude for the EGM2008 model).

Acknowledgments The authors gratefully acknowledge personnel who assisted in identifying coordinates for various sites: Victor Abalakin, Devin J. Della-Rose, Rudolf Dvorak, Michael Feast, Sylvio Ferraz-Mello, Daniel Gambis, Enrico Gerlach, Ian Halliday, Jean Kovalevsky, Jan Krynski, Zinovy Malkin, Leslie Morrison, Craig Niemi, Paul Paquet, Elena Schilbach, and Miguel Vallejo. The authors also thank James Kindig, Dan Mullaney and Susan Cropp, for bringing certain historical publications to our attention, and David LeDoux, for his assistance with the ERTM2160 data sets. Finally, the authors are grateful to Dennis McCarthy, Zuheir Altamimi and an anonymous reviewer for valuable suggestions that improved this manuscript.

Open Access This article is distributed under the terms of the Creative Commons Attribution 4.0 International License (http://creativecomm ons.org/licenses/by/4.0/), which permits unrestricted use, distribution, and reproduction in any medium, provided you give appropriate credit to the original author(s) and the source, provide a link to the Creative Commons license, and indicate if changes were made.

\section{References}

Aoki S, Guinot B, Kaplan GH, Kinoshita H, McCarthy DD, Seidelmann PK (1982) The new definition of universal time. Astron Astrophys 105:359-361

Altamimi Z, Collilieux X, Métivier L (2012) Analysis and results of ITRF2008. (IERS Tech. Note No. 37) Frankfurt am Main: Verlag des Bundesamts für Kartographie und Geodäsie. http://www.iers. org/TN37

Atkinson R (1957) The longitude of Herstmonceux. The. Observatory $77: 31$

BIH (1933) Bureau International de l'Heure Bulletin Horaire 10 Aug 1933:38

BIH (1985) Bureau International de l'Heure annual report for 1984. Observatoire de Paris

Black HD, Gebel G, Newton RR (1984) The centenary of the prime meridian and international standard time. Johns Hopkins APL Tech Dig 5(4):381-389

Bomford G (1980) Geodesy, 4th edn. Clarendon Press, Oxford

Boucher C, Altamimi Z (1985) Towards an improved realization of the BIH Terrestrial Frame. In: Mueller (ed) Proceedings of the international conference on Earth rotation and reference frames, MERIT/COTES Report, vol 2, 31 July-2 August, 1985, Ohio State University, Columbus, OH, USA

Boucher C, Altamimi Z (1986) Status of the realization of the BIH Terrestrial System. In: Babcock AK, Wilkins GA (eds) The Earth's rotation and reference frames for geodesy and geodynamics, Symposium no. 128, International Astronomical Union. Kluwer Academic, Dordrecht, p 107

Defense Mapping Agency (1987) Department of Defense World Geodetic System 1984-its definition and relationships with local geodetic systems. DMA TR 8350.2. Headquarters DMA, Washington, DC, Department of Defense Joint Services WGS Implementation Committee (1967) Department of Defense World Geodetic System 
1966. Defense Intelligence Agency technical report (declassified 30 Dec. 1993)

Department of Defense Joint Services WGS Implementation Committee (1967) Department of Defense World Geodetic System 1966 Part II, Parameters and graphics for practical application of WGS 66

Dillon SC, Gebel G, Pryor LL (1977) Navigation at the prime meridian revisited. Navig J Inst Navig 24(3):264-266

Dolan G (2003) On the line: the story of the Greenwich meridian. National Maritime Museum, Greenwich

Ekman M, Ågren J (2010) Reanalysing astronomical coordinates of old fundamental observatories using satellite positioning and deflections of the vertical. Small Publications in Historical Geophysics 21. Summer Institute for Historical Geophysics, Åland Islands

Explanatory Supplement to the Astronomical Ephemeris and The American Ephemeris and Nautical Almanac (1961). Her Majesty's Stationery Office, London

Feissel M (1980) Determination of the Earth rotation parameters by the Bureau International de l'Heure, 1962-1979. Bull Géod 54:81102

Gebel G, Matthews B (1971) Navigation at the prime meridian. Navig J Inst Navig 18(2):141-146

Gething PJD (1954) The collimation error of the Airy Transit Circle. Mon Not R Astron Soc 114:415

Guinot B (1979) Irregularities of the polar motion. In: McCarthy DD, Pilkington JDH (eds) Time and the Earth's rotation, proceedings of IAU symposium 82. D Reidel, Dordrect, p 280

Guinot B (2000) History of the Bureau International de l'Heure. In: Dick S, McCarthy D, Luzum B (eds) Polar motion: historical and scientific problems, proceedings of IAU colloquium 178. Astr. Soc. Pacific Conference Series 208, pp 175-184

Heiskanen WA, Moritz H (1967) Physical geodesy. W.H. Freeman and Co, San Francisco

Hirt C, Kuhn M, Claessens SJ, Pail R, Seitz K, Gruber T (2014) Study of Earth's short-scale gravity field using the high-resolution SRTM topography model. Comput Geosci 73:71-80. doi:10.1016/ j.cageo.2014.09.00

Howse D (1997) Greenwich time and the longitude. Oxford University Press, Oxford

Hughes J, Espenschied P, McCarthy D, Scott DK, Van Flandern TC (1975) Coordinates of U.S. Naval Observatory installations. Circular 153, U.S. Naval Observatory, Washington

IAU (1977) Resolution 10, Commission 4 recommendation 3(c). In: Müller EA, Jappel A (eds) Proceedings of the sixteenth General Assembly, Grenoble 1976. Trans IAU XVIB, International Astronomical Union

IAU (1980) Resolution of Commissions 4, 19, and 31. In: Wayman PA (ed) Proceedings of the seventeenth General Assembly, Montreal 1979. Trans IAU XVIIB, International Astronomical Union

IERS Reference Meridian (2014) Wikipedia, The Free Encyclopedia. http://en.wikipedia.org/w/index.php?title=IERS_Reference_ Meridian\&oldid=633086624. Accessed 17 Dec 2014

IERS (2010) IERS technical note 36, IERS conventions (2010) IERS Conventions Centre. Verlag des Bundesamts fur Kartographie und Geodasie, Frankfurt am Main

IERS (2014) IERS annual report 2013. In: Dick WR, Thaller D (eds) International Earth rotation and reference systems service, Central Bureau. Verlag des Bundesamts für Kartographie und Geodäsie, Frankfurt am Main, 2014. http://www.iers.org/IERS/EN/ Publications/AnnualReports/AnnualReport2013.html?nn=94904
Jekeli C (2006) Geometric reference systems in geodesy. Lecture Notes, Division of Geodesy and Geospatial Science, School of Earth Sciences, Ohio State University, Columbus

Jennings C (1999) Greenwich: the place where days begin and end. Little Brown and Company, London

Kaplan GH (ed) (1981) The IAU resolutions on astronomical constants, time scales, and the fundamental reference frame. Circular 163, U.S. Naval Observatory, Washington

MacDonald AS (1985) The ordnance survey and the Greenwich meridian. Vistas Astron 28:289-304

Malin S, Stott C (1989) The Greenwich meridian. Ordnance Survey, Southampton

Malys S (1988) Dispersion and correlation among transformation parameters relating two satellite reference frames. Rep. 392, Dept. of Geod. Sci. and Surv., Ohio State University, Columbus

Mautz R (2004) Degree confluence project: $51^{\circ}$ (visit \#2). http:// confluence.org/confluence.php?visitid=10714 Accessed 14 Jan 2015

Mueller II (1969) Spherical and practical astronomy as applied to geodesy. Ungar, New York

Murdin P (2009) Full meridian of glory. Springer, New York

National Geospatial-Intelligence Agency (NGA) Standardization Document (2014) Department of Defense World Geodetic System 1984-its definition and relationships with local geodetic systems, version 1.0.0. NGA.STND.0036_1.0.0_WGS84

National Imagery and Mapping Agency Technical Report 8350.2 (1997) Department of Defense World Geodetic System 1984, its definition and relationships with local geodetic systems, 3 rd edn

Pavlis NK, Holmes SA, Kenyon SC, Factor JK (2012) The development and evaluation of the Earth Gravitational Model 2008 (EGM2008). J Geophys Res 117:B04406. doi:10.1029/2011JB008916

Robbins AR (1967) Time in geodetic astronomy. Surv Rev 19(143):1116

Schmid HH (1974) Three-dimensional triangulation with satellites. NOAA, Rockville, pp 17-19

Seppelin T (1974) The Department of Defense World Geodetic System 1972, Defense Mapping Agency, Washington, DC. Presented at: International symposium on problems related to the redefinition of North American Geodetic Networks, Fredericton, NB, Canada

Sinclair A (1997) The longitude of Greenwich. http://www.rmg. co.uk/explore/astronomy-and-time/astronomy-facts/history/ the-longitude-of-greenwich. Accessed14 Jan 2015

Torge W (2001) Geodesy, 3rd completely revised and extended edn. Walter de Gruyter, Berlin

Tscherning CC (1986) Estimation of the longitude bias of the NWL9D coordinate system from deflections of the vertical, satellite altimetry and high degree spherical harmonic expansions. Bull Géod 60:29-36

Wilkins GA (2000) Project MERIT and the formation of the International Earth Rotation Service. In: Dick S, McCarthy D, Luzum B (eds) Polar motion: historical and scientific problems, proceedings of IAU colloquium 178. Astr. Soc. Pacific Conference Series 208, pp 187-200

Wong RF, Rollins CM, Minter CF (2012) Recent updates to the WGS 84 reference frame. In: Proceedings of the 25th international technical meeting of the Satellite Division of the Institution of Navigation (ION GNSS 2012), Institute of Navigation, Manassas, VA, pp 1164-72 